\title{
Investigating the Performance, Reduction of Emission and Combustion Characteristics of YSZ Coated D.I. Diesel Engine Powered by Binary Bio-fuels
}

\author{
ANANDAVELU KOTHANDAPANY ${ }^{*}$, VISWANATH KRISHNAN ${ }^{2}$ \\ ${ }^{1}$ Department of Mechanical Engineering, M.R.K. Institute of Technology, Kattumannarkoil, Tamilnadu, India \\ ${ }^{2}$ Department of Mechanical Engineering, M.R.K. Institute of Technology, Kattumannarkoil, Tamilnadu, India
}

\begin{abstract}
Performance, emission and combustion studies were carried out on the ceramic coated diesel engine (YSZ) fed with biodiesel obtained from the oil derived from the mango seeds (MSBD) and MSBD blended with turpentine oil (MSBTO). The performance study showed that the MSBD and MSBTO blends showed $3.6 \%$ and $7.1 \%$ more BSFC value compared to that of DF in ceramic coated engine due to higher density and viscosity. The maximum brake thermal efficiency was observed $28 \%$ for DF in coated engine compared to other fuels due to less fuel consumption of DF because of lower density. The emission characteristics displayed that the MSBTO fuel showed 12\%, 15.2\% and $29.1 \%$ reduction in the smoke density, $N O_{x}$ and $C O$ respectively compared to that of DF in coated engine. However, the MSBD and MSBTO showed 17 and $21 \%$ more release of UBHC at full conditions compared to that of DF in ceramic coated engine due to lesser calorific values of MSBD and MSBTO compared to the calorific value of DF. Combustion study revealed that the MSBD and MSBTO displayed less cylinder pressure compared to that of DF in coated engine and the MSBTO fuel showed the 5.3\% decrease in the cylinder pressure compared to that of DF in coated engine owing to less heat liberation and lower cetane value. HRR followed the similar trend of variation of cylinder pressure and the MSBTO displayed 7.4\% lower HRR compared to that of DF in coated engine.
\end{abstract}

Keywords: Binary bio-fuel, Mango seed oil, Emission, Thermal barrier, Combustion, Turpentine oil

\section{Introduction}

Normally Diesel engine is used as prime movers in most of the transports and industrial applications such as buses, lorries, vessels, farm facilities etc. due to its higher thermal efficiency. However, diesel engine emits harmful gases like carbon dioxide, carbon monoxide, smoke, particulates and nitrogen oxide that lead to global warming and human health issue. Bio-fuels are attracted by the researchers to solve the aforementioned issues and to improve the fuel economy [1]. Bio-fuels are derived from the natural vegetation and hence do not harm the environment and renewable resources of nature. Many investigators have tried to use the bio-fuel as addition to the diesel fuel to reduce the fuel consumption of the engine and its pollutants [2-4]. Singh et al. observed that the emission characteristics and combustion parameters of argemone bio-fuel blended with diesel and reported that the bio- fuel showed better performance at part load and high load as compared to lower load. Further, the engine operated with bio-fuel blends produce $6 \%$ increment in brake thermal efficiency as compared to neat diesel fuel and significantly reduced the emissions of harmful pollutants [5].

Mango seed oil is derived from the kernel of mango that is semi-solid at room temperature and becomes a complete liquid while heating. By means of transesterification process, Methyl ester is produced from mango seed oil and used as biodiesel in many applications [6-7]. Srinivas et al. conducted the investigation on the diesel engine using methyl ester of mango seed oil with the injection pressure of 200 bar and examined the performance parameters and combustion characteristics. It is reported that the biodiesel extracted from mango seed oil gives the similar type of characteristics as

*email: anandavel01@yahoo.com 
plain diesel fuel [8]. Savariraj et al. examined the parameter related to the performance and characteristics of combustion of the diesel engine using the pure mango seed oil and biodiesel. The results showed that the biodiesel has decreased specific fuel consumption and improved brake thermal efficiency of the engine for mango seed biodiesel compared to that of mango seed oil. The emission test revealed that the mango seed biodiesel has lesser $\mathrm{NO}_{\mathrm{x}}$ emission compared to the $\mathrm{NO}_{\mathrm{x}}$ emission of neat diesel fuel [9].

Turpentine oil is the oil composed of turpenes that is extracted from pine tree. Several researchers have performed the investigation on using the oil extracted from pine tree (turpentine oil) in diesel engines [10-11]. Rao et al. conducted experiment on the engine performance using turpentine oil with diesel as fuel and reported that at full load, the $30 \%$ blend has 3\% decreased brake thermal efficiency. The emission test showed that the smoke emission, carbon monoxide and hydrocarbon was reduced by $62 \%, 75 \%$ and $65 \%$ respectively, while using turpentine oil as fuel in comparison with diesel fuel [12]. In recent times, the investigators have focused on the binary fuel mode usage in diesel engine and several reports have been identified while performing the literature review [13-15]. For example, Ashour et al. investigated in the diesel engine fed with binary fuels, parameters of the performance, and characteristics of combustion and emission analysis. The results showed that the binary fuel has lesser brake specific fuel consumption by $8 \%$ and $6 \%$ respectively compared to pure diesel fuel. Further, there was drastic reduction in $\mathrm{NO}_{\mathrm{x}}$ and $\mathrm{CO}$ emission by $39 \%$ and $50 \%$ respectively as compared to plain diesel (5\% paraffinic solvent with $95 \%$ diesel) [16]. The important issue faced by researchers in diesel engine is the heat rejection. Most of the heat generated inside the engine during power stroke is rejected by engine components. Heat rejection of engine components could be prevented by performing a thermal barrier coating on the components and many studies have dealt this issue and obtained the feasible results [17-18]. Based on the studies of the literature, it is revealed that, the binary fuel have showed improved performance on the diesel engine and the thermal barrier coating on the engine significantly improved the engine performance parameters and decreased the release of harmful pollutants.

As mango seeds are readily available in the local farms abundantly, the waste disposal of mango seeds is another issue faced by environmentalists. Hence, in this investigation, it is planned to prepare a biodiesel from the oil extracted from the kernel of mango and blended with turpentine oil to obtain the binary fuel effect and to use as bio-fuel in the YSZ coated diesel engine and to evaluate the parameters related to the performance, emission and combustion characteristics of the diesel engine.

\section{Materials and methods}

\subsection{Biodiesel production}

A b und a n t of mango seeds were collected from the local farms and are used for preparation of biodiesel. The detailed procedure is described as follows. Initially the seeds were made to dry for about 15 days at room temperature and then the inner seed or kernel was obtained by breaking the outer shell of the seed. The kernel was dried again for about 5 days at room temperature, broken into fine pieces and then allowed into a crusher for crushing process where the oil was extracted and filtered for the experimental process. The obtained mango seed oil is in pale yellow color, and has less volatility with mixture of hydro carbons. The transesterification process method was followed for producing biodiesel from the oil extracted from the mango seeds. In this study, required quantity of mango seed oil was taken and it is heated up to $60^{\circ} \mathrm{C}$. Then $180 \mathrm{~mL}$ of methanol and $14 \mathrm{~g}$ of $\mathrm{KOH}$, which acted as catalyst, were added. The percentage of alcohol and catalyst used for this process was optimized for maximum conversion. The magnetic stirrer was used for $10 \mathrm{~min}$ at a constant $1500 \mathrm{rpm}$ for stirring. The same process was continued for $2 \mathrm{~h}$ to obtain glycerol and methyl ester. During this process the glycerol was deposited at the bottom due to gravity. And finally the mango seed methyl ester was obtained by filtration process. For this investigation Turpentine oil was purchased from the Siva sakthi Enterprises, Chennai, India. Turpentine oil is a commercial fuel extracted from the pine tree by resin fraction method. During the distillation process pinus resin yields two products: turpentine and rosin. 
The physical properties of the turpentine are: It is yellowish in color, opaque in nature, a combustible mixture of hydrocarbon isomers and sticky volatile. In earlier days, the turpentine oil was directly used in engines without any refinement process. As the availability of the Diesel Fuel increased abundantly, the usage of turpentine was reduced considerably. Figure 1 shows the experimental methodology of using binary fuel in I.C. engines. Table 1 shows the properties of the mango seed oil, turpentine and DF. The Table 2 shows the chemical properties of the various fuel blends used in this investigation.

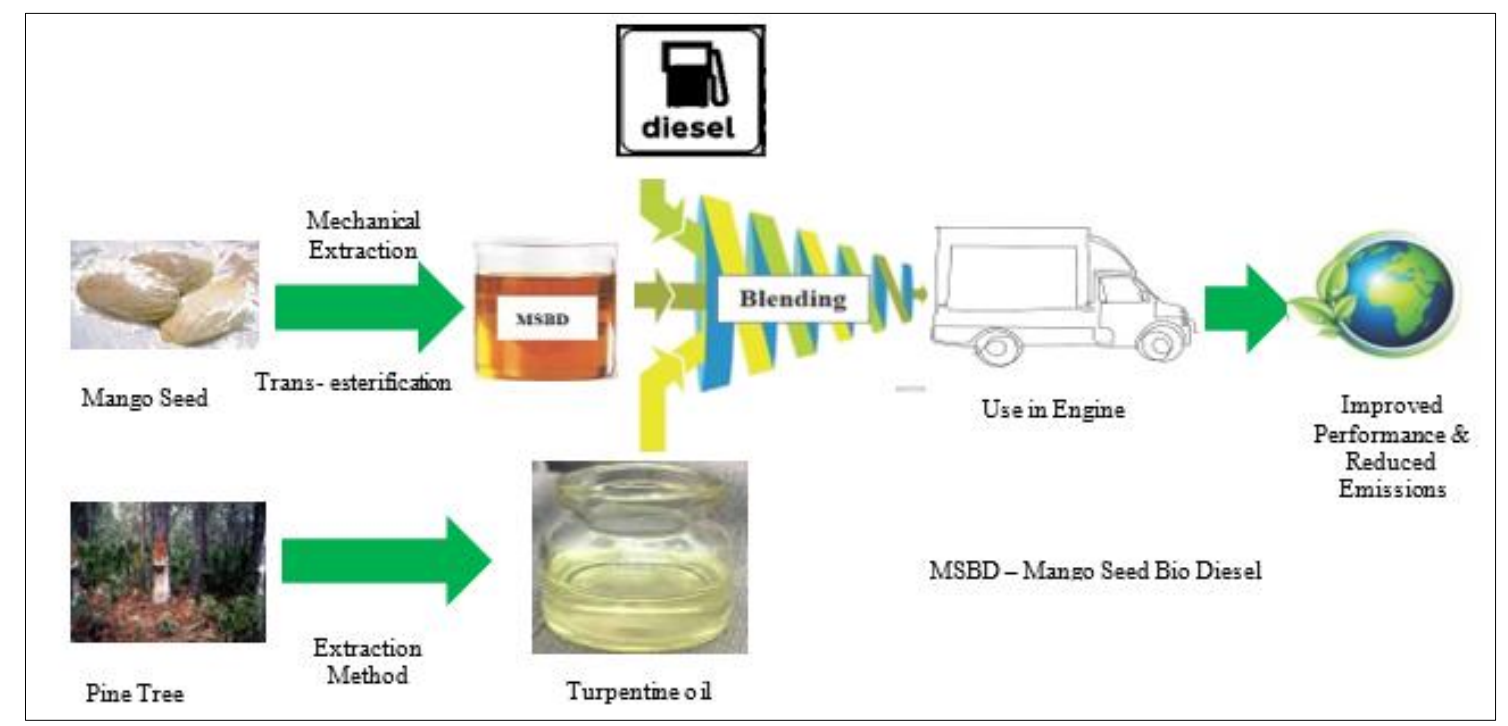

Figure 1. Experimental Methodology of using Binary - Fuel in Engine

\subsection{Thermal barrier coating with Yttria- Stabilized Zirconia (YSZ)}

YSZ is a ceramic powder, used in this investigation as thermal barrier material. Thermal barrier coating was applied on the various engine parts to protect the combustion chamber from heat leakage and to improve the operating temperature. The powder was applied on the various parts of the engine such as valves, cylinder head and piston by thermal spray technique as a thin layer of thickness 300 $\mathrm{m}$. The ceramic powder consisted of $8 \%$ mole yttrium oxide $\left(\mathrm{Y}_{2} \mathrm{O}_{3}\right)$ and $92 \%$ mole zirconia oxide $\left(\mathrm{Z}_{\mathrm{r}} \mathrm{O}_{2}\right)$ and the coated materials are shown in Figure 2.

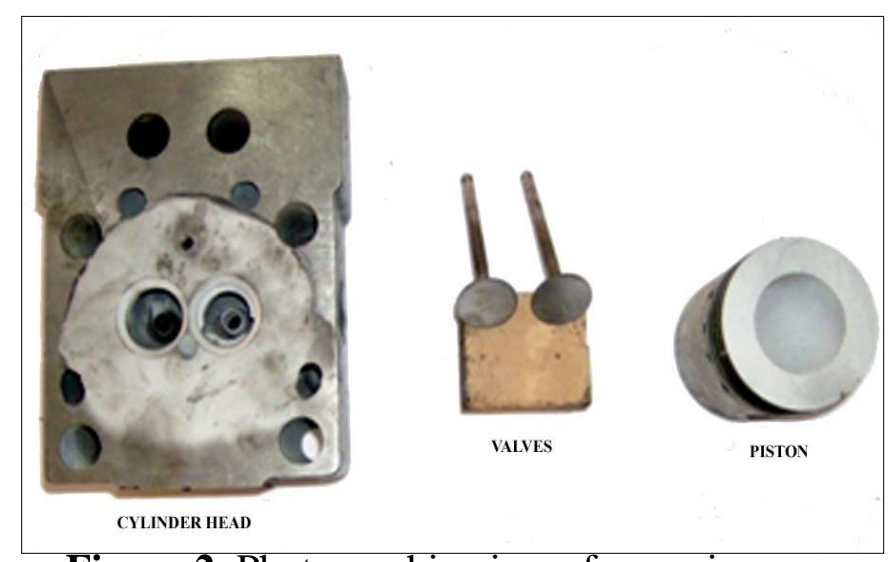

Figure 2. Photographic view of ceramic coated components 
Table 1. Properties of Raw Mango seed oil. MSBD and Turpentine oil

\begin{tabular}{|c|c|c|c|c|c|}
\hline Properties & $\begin{array}{c}\text { Mango } \\
\text { Seed Oil } \\
\text { (Raw) }\end{array}$ & MSBD & Turpentine oil & Diesel & $\begin{array}{c}\text { Requirements as per IS } \\
\text { 1460-1974 }\end{array}$ \\
\hline $\begin{array}{c}\text { Density around } 15 \text { deg.C in } \\
\mathrm{kg} / \mathrm{m}^{3}\end{array}$ & 968 & 894 & 854 & 828 & - \\
\hline $\begin{array}{c}\text { Viscosity (Kinematic) around } 40^{\circ} \mathrm{C} \\
\text { in CST }\end{array}$ & 20.97 & 5.6 & 3.89 & 2.57 & $2.0-7.5$ \\
\hline Flash point in ${ }^{\circ} \mathrm{C}$ & 298 & 168 & 38 & 53 & 38 \\
\hline Fire point in ${ }^{\circ} \mathrm{C}$ & 305 & 174 & - & 58 & 60 max. \\
\hline Heating value in $\mathrm{kJ} / \mathrm{kg}$ & 39580 & 40223 & 44400 & 44680 & - \\
\hline Calculated cetane number & 48 & 48 & 38 & 50 & 42 \\
\hline
\end{tabular}

Table 2. Various blends of fuel and its properties

\begin{tabular}{|c|c|c|c|c|c|}
\hline $\begin{array}{c}\text { Sl.N } \\
\mathbf{0} .\end{array}$ & Fuels & $\begin{array}{c}\text { Blends of Fuel } \\
\text { (\% volume) }\end{array}$ & $\begin{array}{c}\text { Viscosity } \\
\text { (Kinematic) } \\
\text { CST }\end{array}$ & $\begin{array}{c}\text { Calorific } \\
\text { value } \\
\text { (kJ/kg) }\end{array}$ & Density $\left(\mathbf{k g} / \mathbf{m}^{3}\right)$ \\
\hline 1. & DF & $100 \%$ & 3 & 44680 & 828 \\
\hline 2. & MSBD & $\begin{array}{c}25 \% \text { MSBD } \\
+75 \% \text { diesel fuel }\end{array}$ & 3.33 & 43365 & 847 \\
\hline 3. & MSBTO & $\begin{array}{c}25 \% \text { MSBD + 10\% turpentine } \\
\text { oil + } 65 \% \text { diesel fuel }\end{array}$ & 3.37 & 43865 & 846 \\
\hline
\end{tabular}

Table 3. Specifications of the Engine

\begin{tabular}{|c|c|c|}
\hline Model & $:$ & TV1 and Kirloskar make \\
\hline Cooling Type & $:$ & Water cooled \\
\hline Number of cylinder & $:$ & One and Four stroke \\
\hline Maximum power & $:$ & $5.2 \mathrm{Kw}$ \\
\hline Speed & $:$ & $1500 \mathrm{rpm}$ \\
\hline Dynamometer & $:$ & Eddy current \\
\hline Bore & $:$ & $7.5 \mathrm{~mm}$ \\
\hline Stroke & $:$ & $110 \mathrm{~mm}$ \\
\hline Compression ratio & $:$ & $17.5: 1$ \\
\hline Injection timing & $:$ & $23{ }^{\circ} \mathrm{before} \mathrm{TDC}$ \\
\hline Injection pressure & $:$ & $220 \mathrm{~kg} / \mathrm{cm}^{2}$ \\
\hline
\end{tabular}

\subsubsection{Engine Test}

The Kirloskar make water cooled type and compression ignition of the directly injected diesel fuel was used and is shown in the Figure 3. In this study, the engine was loaded by a dynamometer which is an eddy current type. Table 3 describes the engine taken for the experimental work. The speed of the engine was maintained consistently throughout the test. The entire test was repeated for a minimum of three times and the average value is taken for analysis. 


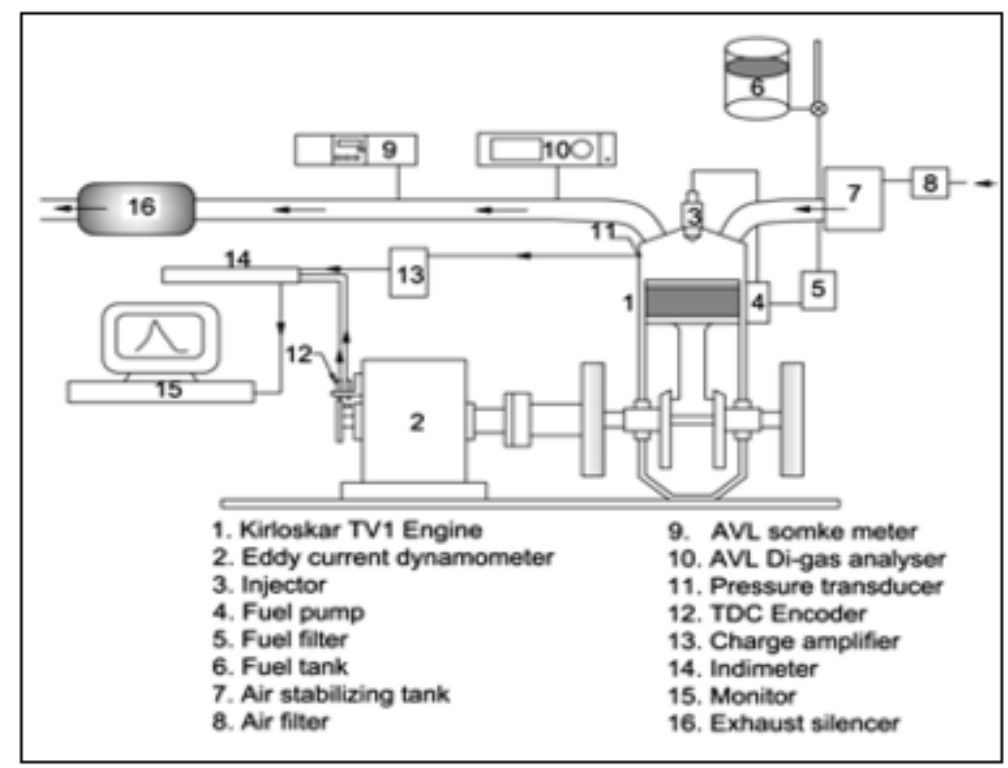

Figure 3. Experimental Setup

\subsubsection{Uncertainity and Error Analysis}

Normally experimental errors and the related uncertainties can occur because of calibration, condition of environment, observation of the reading and the selection of instruments. The percentage of uncertainty is calculated for this experiment is as given below.

$$
\begin{aligned}
& =\sqrt{\begin{array}{l}
\text { Uncertainty of }\left[(T F C)^{2}+(B P)^{2}+(S F C)^{2}+(B T E)^{2}+(H C)^{2}+\left(N O_{X}\right)^{2}\right. \\
+(\text { EGT indicator })^{2}+(\text { Hartidge smoke meter })^{2}+(\text { Pressure Pickup })^{2}
\end{array}} \\
& =\sqrt{\left[(1.0)^{2}+(0.2)^{2}+(1.0)^{2}+(1.0)^{2}+(1.03)^{2}+(0.014)^{2}+(0.15)^{2}+(1.0)^{2}+(0.1)^{2}\right.} \\
& =2.261 \% .
\end{aligned}
$$

Based on the above the total uncertainty was $2.261 \%$. In Table 4, the percentage of uncertainties of

\begin{tabular}{|c|c|c|c|c|}
\hline Type of & \multicolumn{2}{|c|}{ Various Range } & \multirow{2}{*}{$\begin{array}{c}\begin{array}{c}\text { Instruments } \\
\text { Accuracy }\end{array} \\
\pm 0.02 \%\end{array}$} & \multirow{2}{*}{$\begin{array}{r}\text { Percentage } \\
\pm 0.2 \%\end{array}$} \\
\hline Analyzer (Gas) & $\mathrm{CO}$ & $0-10 \%$ & & \\
\hline & $\mathrm{CO}_{2}$ & $0-20 \%$ & $\pm 0.03 \%$ & $=0.09 \%$ \\
\hline & $\mathrm{UBHC}$ & $0-100000 \mathrm{ppm}$ & $=20 \mathrm{ppm}$ & $=1.03 \%$ \\
\hline & $\mathrm{NO}_{x}$ & $0-5000 \mathrm{ppm}$ & $=10 \mathrm{ppm}$ & $=0.014 \%$ \\
\hline Smoke meter & HSÜ & & \pm 0.1 & $\pm 1 \%$ \\
\hline EGT indicator & $0-900^{\circ} \mathrm{C}$ & & $\pm 1^{\circ} \mathrm{C}$ & $\pm 0.15 \%$ \\
\hline Load indicator & $0-100 \mathrm{~kg}$ & & $\pm 0.1 \mathrm{~kg}$ & $\pm 0.2 \%$ \\
\hline Pressure pickup & $0-110$ bar & & $\pm 0.1 \mathrm{~kg}$ & $\pm 0.1 \%$ \\
\hline Crank angle encoder & (3) & & $\pm 1^{\circ}$ & $\pm 0.2 \%$ \\
\hline
\end{tabular}
the various instruments was provided.

Table 4. Experimental instrument uncertainties 


\section{Results and discussions}

\subsection{Parameters related to Performance of the Engine}

\subsubsection{Brake Specific Fuel Consumption (BSFC)}

Figure 4 shows the BSFC of DF, MSBD and MSBTO at varying brake loads. The brake specific fuel consumption of DF in CE showed lower value compared to the BSFC of DF in UCE. While performing a coating on the engine, the heat loss due to radiation is arrested that improves the operating temperature and led to effective combustion of the DF. Hence, the BSFC of DF in CE decreased compared to that of UCE. However, the BSFC of MSBD and MSBTO in coated engine displayed the higher value compared to the BSFC of DF. Due to higher density, more fuel was discharged by the fuel injection pump for the same displacement of the plunger and hence increased the amount consumption of fuel. The BSFC of coated engine measured at rated output power of the engine $(5.2 \mathrm{~kW})$ exhibited as $0.28 \mathrm{~kg} / \mathrm{kWhr}, 0.29 \mathrm{~kg} / \mathrm{kWhr}$ and $0.30 \mathrm{~kg} / \mathrm{kWhr}$ for DF, MSBD and MSBTO. The coated engine consumed 3.6\% more amount of MSBD and $7.1 \%$ more amount of MSBTO compared to DF while operating the engine with biodiesel and dual bio-fuel. Hence, the BSFC slightly increased while using the biodiesel and binary bio-fuel in the coated engine.

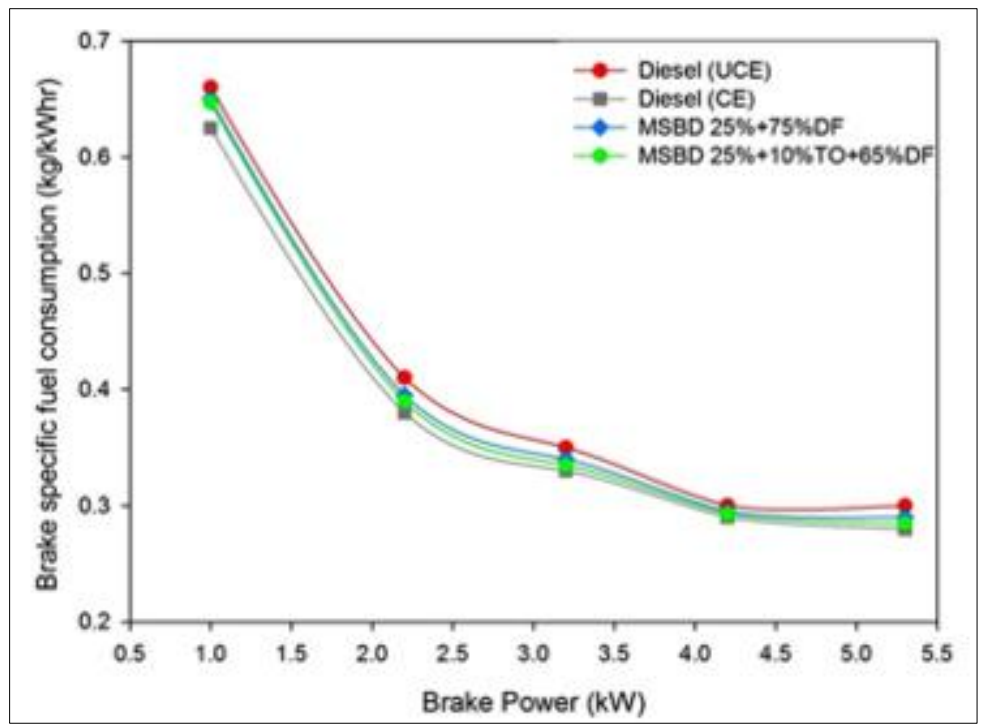

Figure 4. BSFC of various fuel blends

\subsubsection{Brake Thermal Efficiency (BTE)}

The Figure 5 shows the BTE of CE and UCE against brake power (BP). It is obviously observed that the coated engine showed the superior thermal efficiency compared to uncoated engine irrespective of the fuel used because of the effect of YSZ coating on the engine. Ceramic coating (YSZ) decreased the heat rejection from combustion chamber and increased the available energy inside the engine cylinder; because of this complete combustion of the fuel was taken place. Hence, the thermal efficiency of CE exhibited superior value as that of UCE. DF showed the brake thermal efficiency of 28 and 26.5\% measured at rated output power while using in CE and UCE respectively. In case of coated engine, the DF displayed the greater thermal efficiency compared to MSBD and MSBTO due to less consumption of DF and more consumption of MSBD and MSBTO as fuel consumption, which played a major role in brake thermal efficiency. Further, it was noticed that the MSBTO showed the higher BTE owing to the more oxygen content and larger fuel droplets in turpentine oil presented in the MSBTO blend that led to better atomization and complete combustion. 


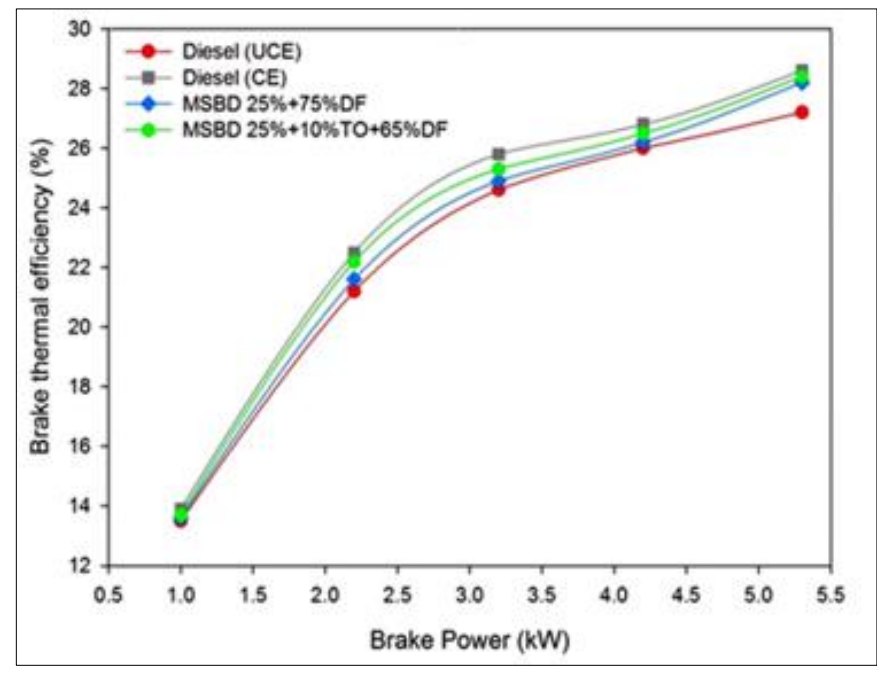

Figure 5. Brake thermal efficiency of various fuel blends

\subsection{Emission parameters}

\subsubsection{Smoke Density (SD)}

Figure 6 implicates the variation of SD for DF, MSBD and MSBTO blends for the different range of brake power. MSBTO blends produced lower SD compared to DF and MSBD blends because of addition of turpentine oil fraction. The turpentine oil fraction in MSBTO blend has higher oxygen content that leads to more HRR during diffusive combustion phase. Further, it showed that a $12 \%$ reduction in SD for MSBTO blends measured at maximum load condition as compared with the DF in coated engine. Moreover, the DF displayed the smoke density of $57 \%$ that is $14 \%$ lower than the smoke density of DF in uncoated engine. The decrease of SD in CE could be due to the longer combustion duration because of ceramic coating that reduced the heat rejection rate.

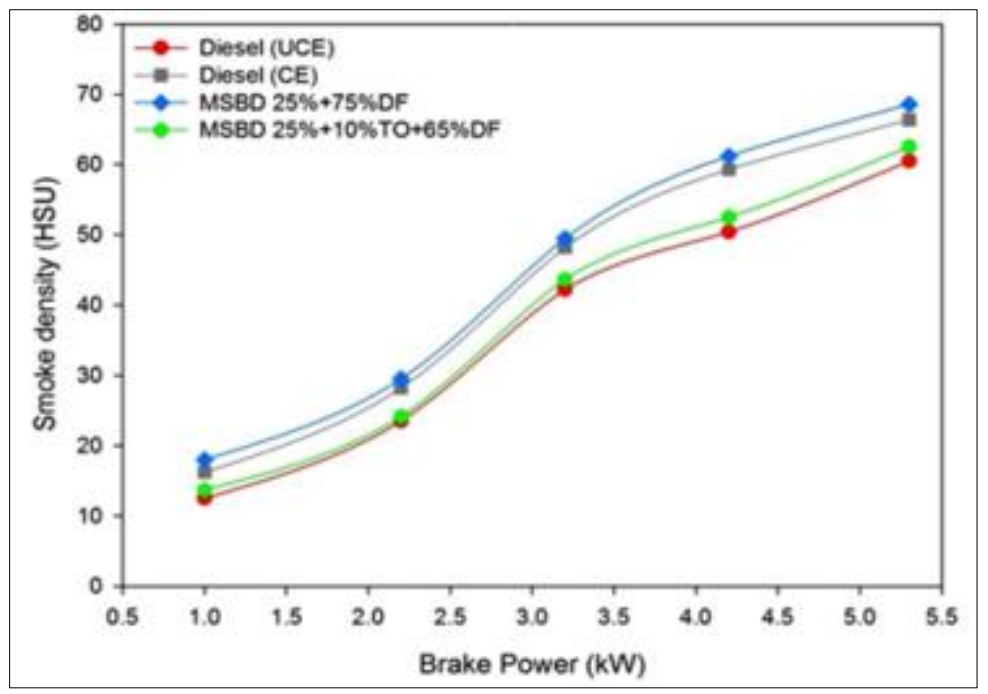

Figure 6. Smoke density of various fuel blends

\subsubsection{Oxides of Nitrogen $\left(\mathrm{NO}_{\mathrm{x}}\right)$}

The $\mathrm{NO}_{\mathrm{x}}$ emission with respect to brake power for DF, MSBD and MSBTO blends was shown in The $\mathrm{NO}_{\mathrm{x}}$ emission with respect to brake power for DF, MSBD and MSBTO blends was shown in the Figure 7. The CE showed higher $\mathrm{NO}_{\mathrm{x}}$ emission compared to that of UCE while using DF. Generally, the combustion temperature plays the important role in the $\mathrm{NO}_{\mathrm{x}}$ emission. The increase of combustion temperature would result increased $\mathrm{NO}_{\mathrm{x}}$ emission. As the coated engine restricted the heat rejection 
from the engine cylinder, the inside cylinder temperature increased and increased the $\mathrm{NO}_{\mathrm{x}}$ emission. Further, the MSBD and MSBTO blends exhibited a less $\mathrm{NO}_{\mathrm{x}}$ emission compared to the DF in coated engine owing to the lower calorific value of the blends (Table 2) compared to DF that decreased the combustion temperature rise and hence NOx emission was reduced. Moreover, the MSBTO blend displayed a lower $\mathrm{NO}_{\mathrm{x}}$ emission compared to that of all other fuels because of the more oxygen content in the MSBTO blend. It was observed that $15.2 \%$ decrement in $\mathrm{NO}_{\mathrm{x}}$ emission for MSBTO blends compared to that of DF in coated engine.

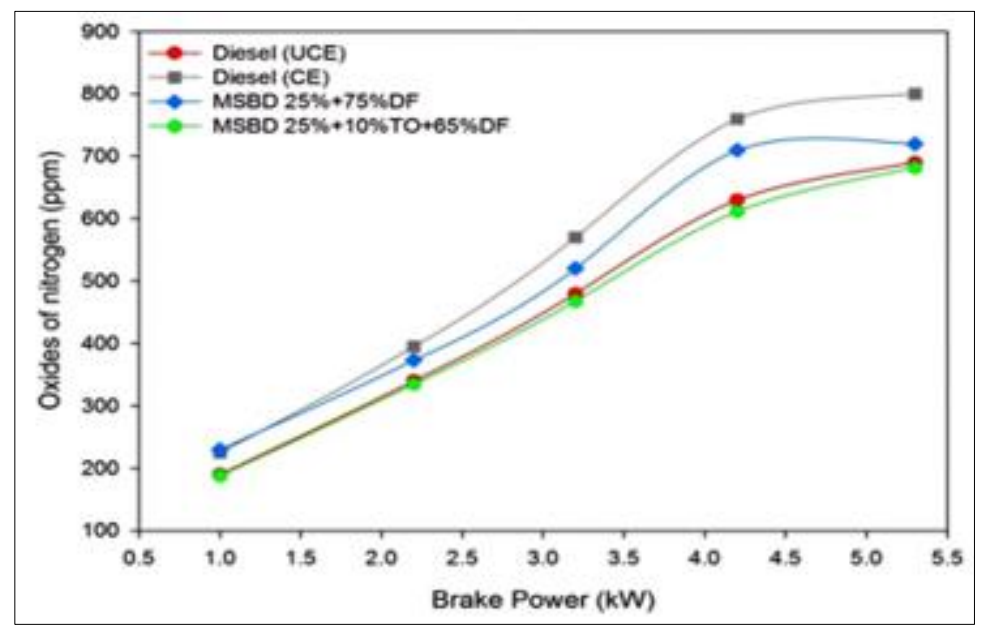

Figure 7. Oxides of nitrogen of various fuel blends

\subsubsection{Carbon Monoxide (CO)}

Figure 8 shows the CO emission of various fuel blends such as DF, MSBD and MSBTO in CE and UCE. It is obviously seen from the Figure 7 that the DF showed less $\mathrm{CO}$ emission in $\mathrm{C} \mathrm{E}$ compared to that of UCE. The CO emission at full load condition decreased from $0.0875 \%$ to $0.0725 \%$ while using DF in CE. The emission of CO is the function of oxygen and temperature. As the CE retained more heat inside the cylinder due to ceramic coating, the combustion temperature increased and decreased the CO emission. Further, the MSBD and MSBTO displayed lower CO emissions compared to the $\mathrm{CO}$ emission of DF in $\mathrm{CE}$ due to the availability of sufficient oxygen presented with in the biofuels as bio-fuels are oxygenated fuels. In addition, the MSBTO blend showed the very low CO emissions by 8.3 and $29.1 \%$ compared to the CO emission of MSBD and DF in CE because of the presence of more oxygen content in MSBTO blends.

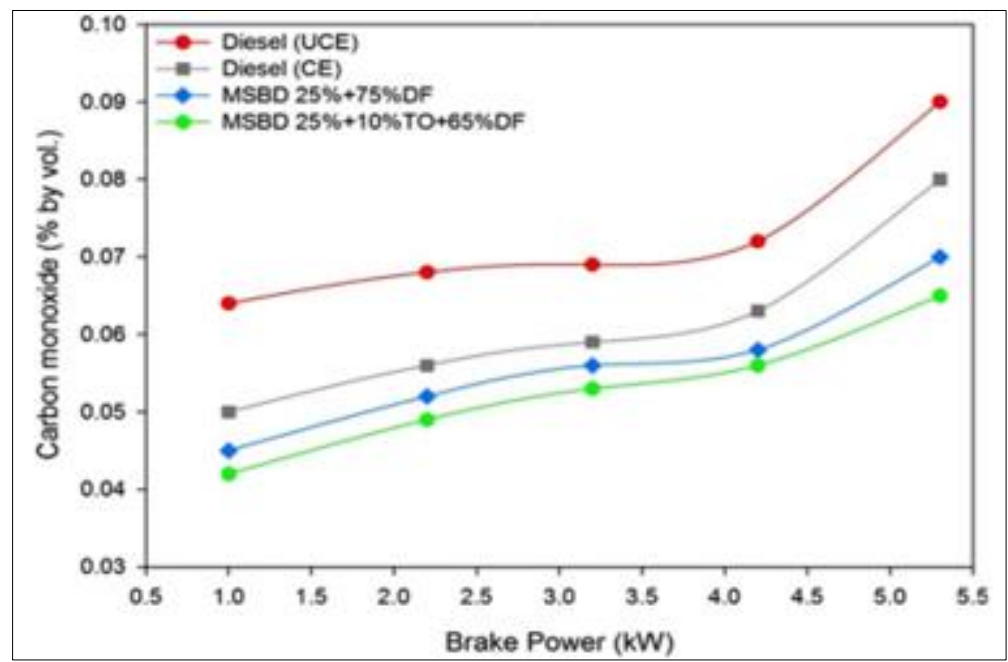

Figure 8. Carbon Monoxide of various fuel blends 


\subsubsection{Unburnt Hydrocarbon (UBHC)}

Figure 9 shows the UBHC emission of DF, MSBD and MSBTO against brake power in CE and UCE. The DF showed lesser UBHC emission in CE compared to that of UCE due to the superior operating temperature of CE. However, the bio-diesels such as MSBD and MSBTO displayed higher UBHC emission compared to that of DF in coated engine. As the calorific value of the bio-diesels was lesser than the calorific value of DF, more bio-diesel fuels was consumed by engine to produce the similar output power and liberated more UBHC due to more fuel in the engine cylinder. Further, the viscosity of the bio-diesel played another role in the emission of UBHC. As the viscosity of the biodiesel was greater than the viscosity of DF, the combustion process was delayed due to more time taken for the breakage of the bond between the elements of bio-diesel and led to the incomplete combustion and expelled more UBHC. At full load condition, the MSBD and MSBTO blend exhibited 17 and $21 \%$ increase in UBHC compared to that of DF in CE.

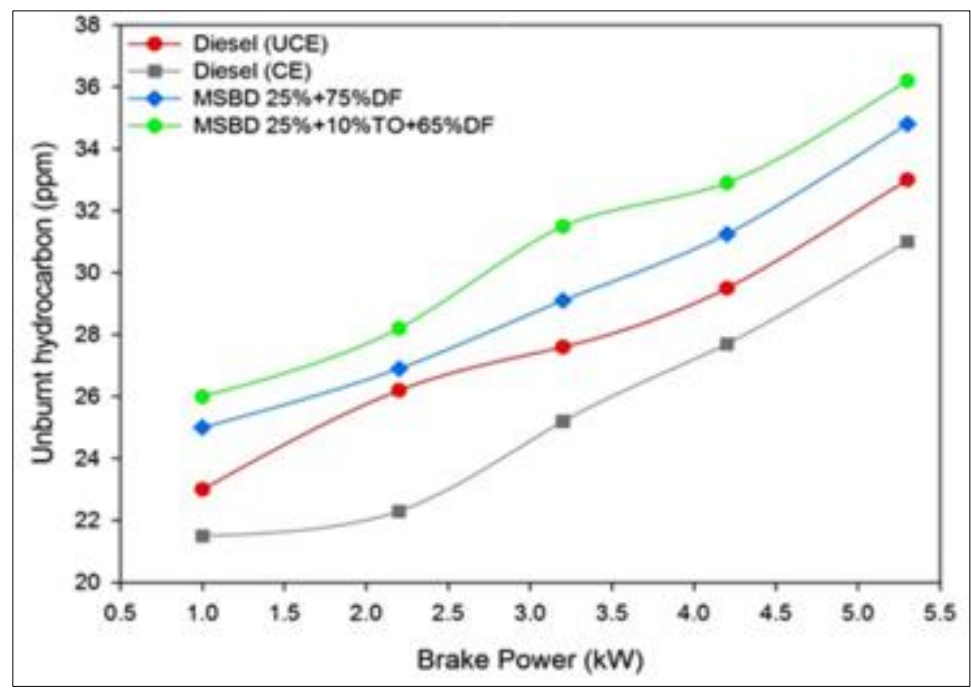

Figure 9. Unburnt hydrocarbon of various fuel blends

\subsection{Combustion Analysis}

\subsubsection{Cylinder Pressure (CP)}

The variation of CP with respect to crank angle for DF, MSBD and MSBTO blends was shown in the Figure 10. The DF showed higher cylinder pressure compared to that of MSBD and MSBTO blends in CE. As the calorific value of DF is superior to the calorific value of MSBD and MSBTO, the $\mathrm{DF}$ displayed greater cylinder pressure due to more heat release during the power stroke of the engine. The bio-fuels MSBD and MSBTO liberated less heat compared to DF as the calorific value of biofuels was lesser than the calorific value of DF. Further, the cetane number plays the important role in the cylinder pressure. Higher cetane number would decrease the ignition delay and vice versa. The cetane number of the MSBD and MSBTO blends was lower as compared to DF and hence increased the ignition delay that led to the combustion of less quantity of fuel. Moreover, the maximum cylinder pressure for MSBTO blends in coated engine was measured as 76.019 bar that is $5.3 \%$ lower than the cylinder pressure for DF. It was found that the MSBD, MSBTO blends and DF produced the peak pressure within the range of 5 to 15 degree crank angle after TDC. Because of this, there is high burning rate at the initial stage. Hence, it was concluded that the operation of the engine with the binary fuels showed no combustion related problems. 


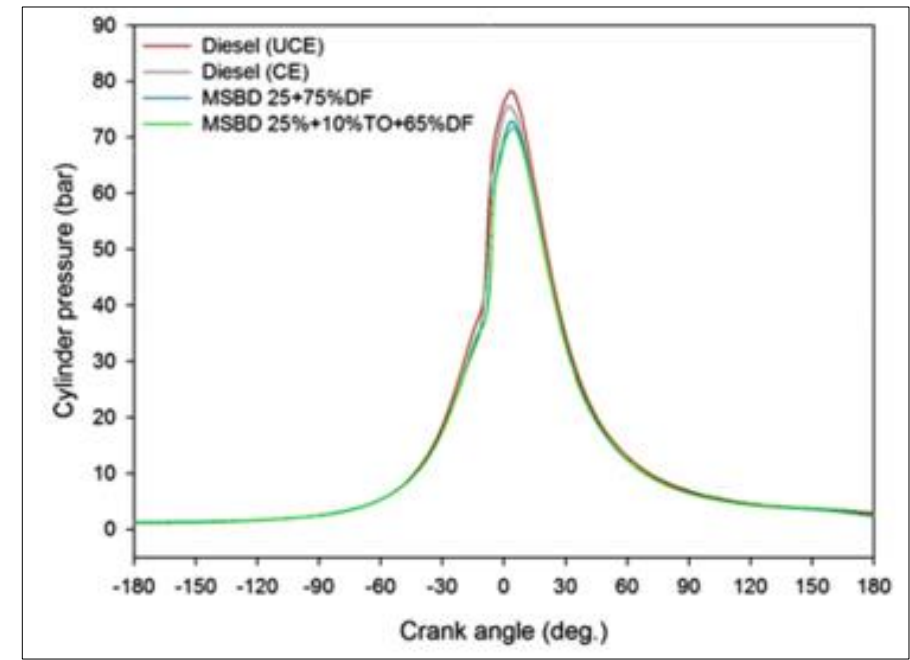

Figure 10. Cylinder pressure of various fuel blends

\subsubsection{Heat Release Rate (HRR)}

Figure 11 shows the variation of HRR of DF, MSBD and MSBTO blends. The DF showed HRR and the bio-fuels such as MSBD and MSBTO displayed lower HRR compared to that of DF in CE. The HRR of DF measured at full load in UCE and CE as $121.650 \mathrm{~kJ} / \mathrm{m}^{3} \mathrm{deg} \& 100.98 \mathrm{~kJ} / \mathrm{m}^{3} \mathrm{deg}$ respectively. The MSBTO blend exhibited the lowest HRR of $94.05 \mathrm{~kJ} / \mathrm{m}^{3}$ deg measured at full load in CE that is $7.4 \%$ lower than the HRR of DF. The peak HRR for MSBTO blends was advanced approximately 4-5 degrees in $\mathrm{CE}$ that in turn increased the heat losses and friction losses. This could be attributed due to slow burning and the lower internal energy of MSBTO blends because of its lower calorific value and slight increase in density.

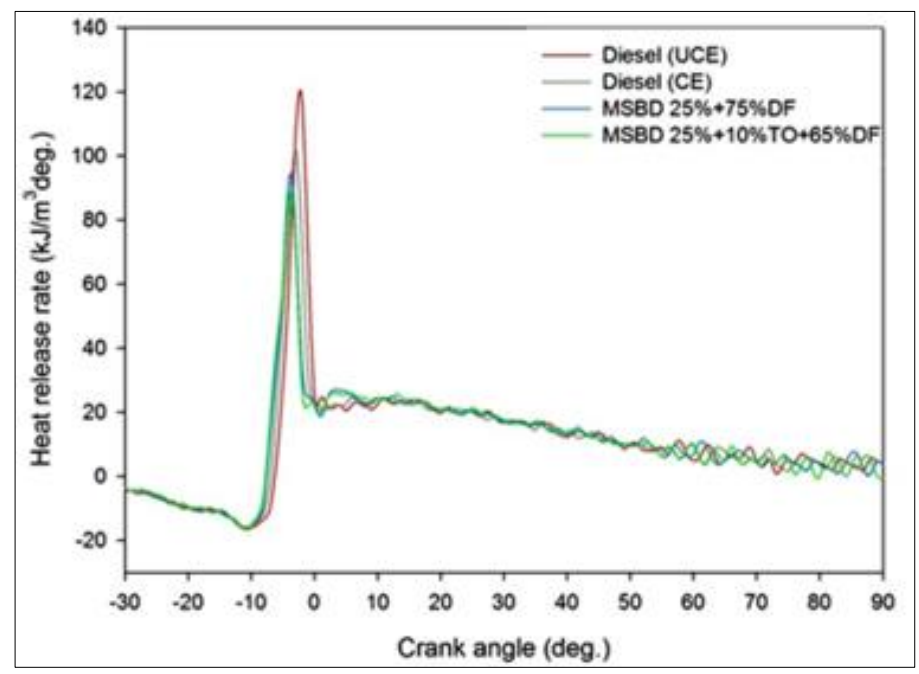

Figure 11. Heat release rate of various test fuel

\section{Conclusions}

Experimental work and investigation was carried out on YSZ coated diesel engine using the binary bio-fuel namely mango seed oil and turpentine oil and the performance parameters, emission and combustion characteristics were an alyzed. Based on this, the following conclusions were made.

The CE consumed less DF compared to that of UCE due to the superior operating temperature of the coated engine. The BSFC of bio-fuels MSBD and MSBTO showed greater values compared to the BSFC of DF in coated engine owing to the higher viscosity and density of bio-fuels. At full load 
condition, the engine consumed 3.6 and 7.1\% more MSBD and MSBTO respectively compared to DF in CE.

BTE of CE showed improved value compared to that of UCE due to the restriction of heat rejection from the engine cylinder and displayed 28 and $26.5 \%$ while using DF in coated and uncoated engine respectively. The bio-fuels MSBD and MSBTO exhibited less brake thermal efficiencies compared to DF in coated engine owing to more consumption of MSBD and MSBTO for the same power.

MSBTO blends showed lower smoke density value compared to that of DF in CE and exhibited $12 \%$ decrement in the smoke density compared to the DF measured at full load condition. This is due to the better HRR of the MSBTO fuel blends as compared to other fuels.

MSBTO displayed $15.2 \%$ and $29.1 \%$ reduction in $\mathrm{NO}_{\mathrm{x}}$ and $\mathrm{CO}$ emission respectively compared to that of DF in CE due to the presence of more oxygen content in the MSBTO blends leads to the complete combustion and the DF showed higher $\mathrm{NO}_{\mathrm{x}}$ emission in CE owing to the superior operating temperature of the engine compared to that of UCE.

UBHC values of MSBD and MSBTO showed greater values compared to DF in CE. This is due to the lower calorific value of MSBD and MSBTO blends and displayed 17 and 21\% respectively.

The peak cylinder pressure of MSBD and MSBTO blends displayed lower values compared to that of DF fuel in CE and the MSBTO blends displayed 5.3\% less cylinder pressure compared to that of DF in CE due to the lesser heat liberation and lower cetane value of the MSBTO.

The HRR followed the same trend of variation of cylinder pressure and the MSBTO fuel exhibited 7.4\% less HRR compared to that of DF in CE measured at full load conditions.

\section{References}

1.KUMAR, H., SARMA, A.K., KUMAR, P. A., comprehensive review on preparation, characterization, and combustion characteristics of micro emulsion based hybrid biofuels. Renewable and Sustainable Energy Reviews, 117, 2020, p.109498.

2.ERDOĞAN, S., AYDIN, S., BALKI, M.K., SAYIN, C., Operational evaluation of thermal barrier coated diesel engine fueled with biodiesel/diesel blend by using MCDM method base on engine performance, emission and combustion characteristics. Renewable Energy, 151, 2020, pp.698-706.

3.SENTHILKUMAR, G., SAJIN, J.B.; YUVARAJAN, D., ARUNKUMAR, T., Evaluation of emission, performance and combustion characteristics of dual fuelled research diesel engine. Environmental Technology, 41(6), 2020, pp.711-718.

4.YESILYURT, M.K., YILBASI, Z., AYDIN, M., The performance, emissions, and combustion characteristics of an unmodified diesel engine running on the ternary blends of pentanol/safflower oil biodiesel/diesel fuel. Journal of Thermal Analysis and Calorimetry, 2020, pp.1-40.

5.SINGH, M., SANDHU, S.S., Performance, emission and combustion characteristics of multi-cylinder CRDI engine fueled with argemone biodiesel/diesel blends. Fuel, 265, 2020, p.117024.

6.PRASANTH KUMAR, B., APPA RAO, K., DHANA RAJU, V., RAMI REDDY, S., MALLIKARJUNA RAO, D., SUBBA REDDY, J., Experimental Investigation on the Performance and Emission Characteristics of a Diesel Engine Powered with Waste Mango Seed Biodiesel Blends. International Journal of Ambient Energy, (just-accepted), 2019, pp.1-29.

7.VIJAYARAJ, K., SATHIYAGNANAM, A.P., Experimental investigation of a diesel engine with methyl ester of mango seed oil and diesel blends. Alexandria Engineering Journal, 5(1), 2016, pp.215221.

8.SRINIVAS, V., POSANGIRI, A.R., Performance and Emission Characteristics of Methyl Ester Mango Seed Biodiesel on Four Stroke Single Cylinder Diesel Engine with 200 bar Injection Pressure. International Journal of Engineering Techniques, 2018,4(2).

9.SAVARIRAJ, S., SARAVANAN, C.G., GANAPATHY, T., Experimental investigation on Di diesel engine powered with raw mango seed oil (MSO) and mango seed biodiesel (MSBD). International Journal of Engineering Research \& Technology, 2, 2013, pp.1516-1523. 
10.JEEVANANTHAM, A.K., REDDY, D.M., GOYAL, N., BANSAL, D., KUMAR, G., KUMAR, A., NANTHAGOPAL., ASHOK, B., Experimental study on the effect of cetane improver with turpentine oil on CI engine characteristics. Fuel, 262, 2020, p.116551.

11.ANAND, B.P., SARAVANAN, C.G., SRINIVASAN, C.A., Performance and exhaust emission of turpentine oil powered direct injection diesel engine. Renewable Energy, 35(6), 2010, pp.1179-1184. 12.RAO, P.V., CHARY, D.P., Diesel engine performance analysis with blend fuel of biodiesel and Turpentine oil as biofuel additive. International Journal of Engineering, Science and Mathematics, 7(1), 2018, pp.176-182.

13.DURAISAMY, G., RANGASAMY, M., GOVINDAN, N., A comparative study on methanol/diesel and methanol/PODE dual fuel RCCI combustion in an automotive diesel engine. Renewable Energy, 145, 2020, pp.542-556.

14.SENTHILKUMAR, G., SAJIN, J.B., YUVARAJAN, D., ARUNKUMAR, T., Evaluation of emission, performance andcombustion characteristics of dual fuelled research diesel engine. Environmental Technology, 41(6), 2020, pp.711-718.

15.NING, L., DUAN, Q., CHEN, Z., KOU, H., LIU, B., YANG, B., ZENG, K., A comparative study on the combustion and emissions of a non-road common rail diesel engine fueled with primary alcohol fuels (methanol, ethanol, and n-butanol)/diesel dual fuel. Fuel, 266, 2020, p.117034. 16.ASHOUR, M.K., ELWARDANY, A.E., Addition of two kerosene-based fuels to diesel-biodiesel fuel: Effect on combustion, performance and emissions characteristics of CI engine. Fuel, 269, 2020, p.117473.

17.ERDOĞAN, S., AYDIN, S., BALKI, M.K., SAYIN, C., Operational evaluation of thermal barrier coated diesel engine fueled with biodiesel/diesel blend by using MCDM method base on engine performance, emission and combustion characteristics. Renewable Energy, 151, 2020, pp.698-706.

18.KANDASAMY, M., SENTHILKUMAR, D., Combustion and Emission Behaviour of Honge Biofuel in a Thermal Barrier Coated Diesel Engine Suitable for Agriculture. In Recent Trends in Mechanical Engineering, 2020, (pp. 121-127). Springer, Singapore.

Manuscript received: 31.12 .2020 